\title{
Heterozygous Deletion in Exons 4-5 of SHOX Gene in a Patient Diagnosed as Idiopathic Short Stature
}

\author{
Anna David1, Imre Zoltán Kun¹, Gábor Nyírő², Zsuzsánna Szántó1, Attila Patócs²,3 \\ 1 University of Medicine and Pharmacy, Tirgu Mures, Romania \\ 2 Department of Laboratory Medicine, Semmelweis University, Budapest, Hungary \\ 3 MTA-SE Molecular Medicine Research Group, Budapest, Hungary
}

\begin{abstract}
Introduction: Isolated Short Stature Homeobox (SHOX) gene haploinsufficiency can be found in 2-15\% of individuals diagnosed with idiopathic short stature determining different skeletal phenotypes. Case presentation: We present the history of an 11-year-old female patient diagnosed with idiopathic short stature. Clinically, she was moderately disproportionate, with cubitus valgus and palatum ogivale. Her breast development was in Tanner stage 1 at the time of diagnosis. The endocrine diagnostic tests did not reveal any abnormalities except a slightly elevated thyroid stimulating hormone. We have also assessed the bone radiological findings. Multiplex Ligation-dependent Probe Amplification technique used for the identification of SHOX gene haploinsufficiency showed a heterozygous deletion spanning exons 4-5 of SHOX gene. Conclusions: This case is determined by deletions in exons 4-5 of SHOX gene and indicates the necessity of screening for SHOX deletions in patients diagnosed with idiopathic short stature, especially in children having increased sitting height-to-height ratio or decreased extremitiesto-trunk ratio.
\end{abstract}

Keywords: SHOX gene, idiopathic short stature

Received 29 May 2017 / Accepted 24 July 2017

\section{Introduction}

The short stature (SS), found in about 3\% of children worldwide, can occur due to a variety of causes and is diagnosed when the proband's height is below - 2SD (standard deviation) within the mean age, gender and ethnic group of a certain population, or their height is below the third percentile curve. Within a family, short stature means < 2SD of parental height.

Idiopathic short stature (ISS, Online Mendelian Inheritance in Man (OMIM) \#300582) is characterised by the above-mentioned parameters, without any apparent clinical signs of systemic, endocrine, nutritional and chromosomal abnormalities. Clinical diagnosis is based on the negative findings of standard diagnostic procedures. Nowadays more than 200 genes are known to be involved in the aetiology of syndromes characterised by short stature [1, 2]. SHOX gene haploinsufficiency is one of the most common monogenic causes of SS which have been described in $2-15 \%$ of ISS cases, in 50-90\% of patients with Leri-Weill dyschondrosteosis (LWD; OMIM \#127300) and 40\% of patients presenting Langer mesomelic dysplasia (LMD) $[3,4]$. The SHOX gene is located in the pseudoautosomal region 1 (PAR1) of the short arm of the $\mathrm{X}$ and $\mathrm{Y}$ chromosomes (Xp22.33, Yp11.32) [5, 6]. PAR1 genes do not undergo $\mathrm{X}$ inactivation, and two copies of the SHOX gene are expressed, one of each of the sex chromosomes [5]. The SHOX gene encodes a transcription factor expressed during human embryogenesis in the pharyngeal arches and developing limbs. It plays a fundamental role in the chondrocyte function of the growth plate, as a regulator

* Correspondence to: Anna David

E-mail: davidanna.derm@gmail.com of cellular proliferation and differentiation [6, 7]. Isolated SHOX deficiency leads to a variety of different skeletal phenotypes and clinical conditions [3]. The Multiplex Ligation-dependent Probe Amplification (MLPA) is the first recommended molecular genetic method for the detection of deletions in the SHOX-gene and can be used to detect PAR1 deletions and duplications including SHOX and downstream enhancer region [8].

\section{Case presentation}

This study was approved by the local Ethical Committee, the informed consent was signed by the parents, and they approved to publish the medical data of the child.

The subject of our study was an 11-year-old girl from Odorheiu-Secuiesc, who was born full term with a birth weight of 4,000 g and $57 \mathrm{~cm}$ length. Thereafter, compared to other children of her age, she was of short stature. At the age of nine, she was $124.5 \mathrm{~cm}$ tall $(-2.35 \mathrm{SD})$ and she weighed $40 \mathrm{~kg}$. Clinically, she was moderately disproportionate, having increased sitting height-to-height $(\mathrm{SH} / \mathrm{H})$ ratio, with cubitus valgus and palatum ogivale. At the first measurement according to the Tanner scale, her breast development stage was B2/3. Presently (two years later, Figure 1.) she weighs $45 \mathrm{~kg}$, presenting obesity grade 1 (according to the World Health Organisation criteria, year 2007), genu valgum and Tanner stage B3. She also presents cubitus valgus, palatum ogivale (high - arched palate) and micrognathia.

Binder and co-workers have developed a method based on axiological measurement which facilitates a more accurate selection of idiopathic short stature patients to whom the SHOX gene examination is recommended. The authors recommend calculating the sum of leg length and arm 


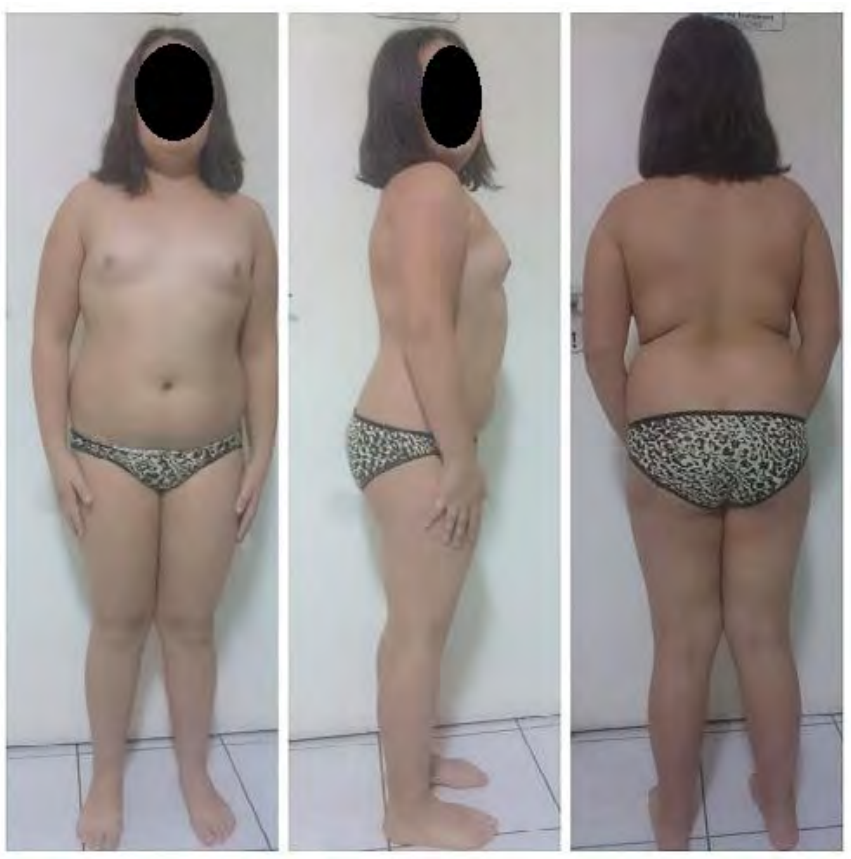

Fig. 1. The SHOX haploinsufficiency ISS patient from Romania

span, divided by sitting height. Thus the results can be of almost $100 \%$ negative predictive value, i.e. the higher this value is $(>2.5)$, the lower the probability of SHOX gene deletion [9].

According to the phenotype scoring system proposed by Rappold and his co-workers for the evaluation of SHOX deficiency, there are eight criteria based on the data of 1608 short individuals including 68 persons with SHOX deficiency that should be taken into consideration [10]. Arm span to height $(\mathrm{A} / \mathrm{H})$ and $\mathrm{SH} / \mathrm{H}$ ratios were classified as abnormal if less than 0.965 and greater than 0.555 , respectively. In our case, the total score was 8 . The patient presented an increased sitting height/height ratio, obesity and cubitus valgus (Table 1).

The common endocrinological diagnostic tests did not reveal any abnormalities which might cause growth retardation, except a slightly elevated TSH $=14.55 \mu \mathrm{IU} / \mathrm{mL}$ (0.25-5.00) (Table 2). Thyroid ultrasound described normal volume and structure, and the anti-thyroid peroxidase antibodies were between normal range excluding the presence of autoimmune thyroid disease. The high TSH level indicated a subclinical hypothyroidism that could be

Table I. The total diagnostic score of our patient, based on axiological measurements and clinical characteristics [10].

\begin{tabular}{lcc}
\hline & Criterion & Score \\
\hline Arm span/height ratio & $<0.965$ & 0 \\
Sitting height/height ratio & $>0.555$ & 2 \\
BMI & $>50$ percentile & 4 \\
Cubitus valgus & present & 2 \\
Short forearm & present & 0 \\
Bent forearm & present & 0 \\
Muscle hypertrophy & present & 0 \\
Ulna elbow dislocation & present & 0 \\
Total score & & 8 \\
\hline
\end{tabular}

related to the elevated BMI. Bone radiological findings excluded the presence of Leri-Weill dyschondrosteosis. Turner syndrome (even a mosaicism) could be excluded by the fact, that in our case only the 4 and 5 exons of the SHOX gene were deleted, and not the whole gene. Similarly, in the positive control Turner syndrome patient only one SHOX gene was present, so the intensity measured with MLPA was only half of the normal controls.

To determine the possible alterations of the SHOX gene, genomic DNA was extracted from the leucocytes by the method recommended by QIAgen, and the Multiplex Ligation-dependent Probe Amplification (MLPA) technique was performed at the Endocrine Genetics Laboratory of the Semmelweis University, using the SALSA P018 MLPA kit (MRC-Holland, Amsterdam, The Netherlands), according to the manufacturer's protocol. Molecular genetic testing revealed a heterozygous deletion of exons 4-5 of SHOX gene, using the MLPA technique (Figure 2).

Short stature was present in the family history of the patient (brother, mother and father), but the genetic testing of the SHOX gene failed to show SHOX gene deletion in the family members, suggesting that this alteration occurred de novo in our patient.

The treatment plan consists of a hypocaloric diet with low fat, low carbohydrates, and protein rich foods. The patient was advised to avoid a sedentary lifestyle and do physical exercise on a daily basis, at least 30-60 min. Systemic treatment for subclinical hypothyroidism with small doses of L-thyroxine was also necessary. Growth hormone therapy has been approved by FDA (Food and Drug Administration) in The United States, and now it is generally accepted in the clinical treatment of these cases [11].

\section{Discussions}

Isolated SHOX haploinsufficiency is one important monogenic cause of short stature. The deletion of SHOX gene is characterized by feminine domination, which can be explained by the fact that the deletion of the short arm of the $\mathrm{X}$ chromosome is more frequent than the rupture of the short arm of the Y chromosome [12].

As far as we know, we are the first to report a case of ISS in a young patient from Romania diagnosed with the MLPA technique for SHOX haploinsufficiency. Our case

Table II. Results of endocrine diagnostic tests.

\begin{tabular}{lcc}
\hline & $\begin{array}{c}\text { Patient's } \\
\text { values }\end{array}$ & Reference range \\
\hline Growth hormone at baseline $(\mathrm{ng} / \mathrm{mL})$ & 2.99 & $0.05-17.3 \mathrm{ng} / \mathrm{mL}$ \\
Insulin-like growth factor type 1 $(\mathrm{ng} / \mathrm{mL})$ & 386.9 & $76-549 \mathrm{ng} / \mathrm{mL}$ \\
Plasma cortisol at baseline, at 8:00 AM $(\mathrm{nmol} / \mathrm{L})$ & 578.8 & $118-618 \mathrm{nmol} / \mathrm{L}$ \\
Anti-thyroid peroxidase antibodies $(\mathrm{IU} / \mathrm{mL})$ & $<10$ & $<35 \mathrm{IU} / \mathrm{mL}$ \\
Thyroid stimulating hormone $(\mu \mathrm{lU} / \mathrm{mL})$ & 14.55 & $0.25-5 \mu \mathrm{lU} / \mathrm{mL}$ \\
Free Thyroxine $(\mathrm{ng} / \mathrm{dL})$ & 1.01 & $0.98-1.63 \mathrm{ng} / \mathrm{dL}$ \\
Glucose $(\mathrm{mg} / \mathrm{dL})$ & 98 & $60-100 \mathrm{mg} / \mathrm{dL}$ \\
Alcaline phosphatase $(\mathrm{U} / \mathrm{L})$ & 208 & $51-332 \mathrm{U} / \mathrm{L}$ \\
\hline
\end{tabular}


A

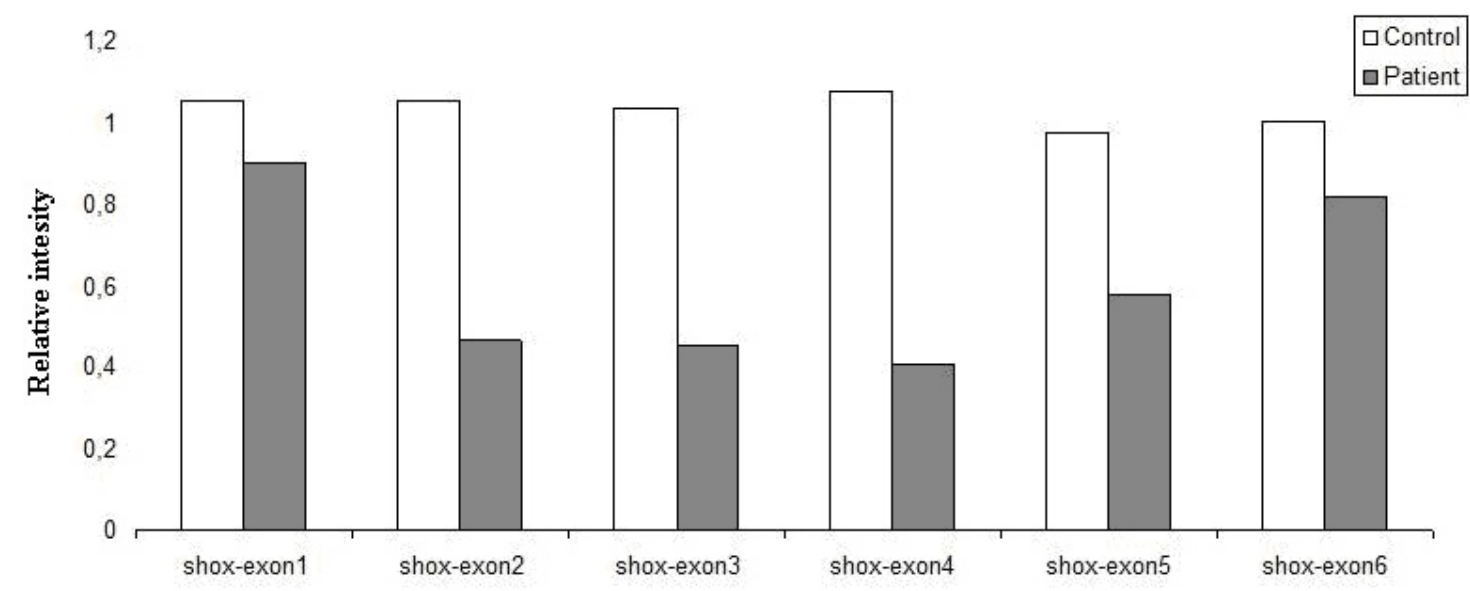

B

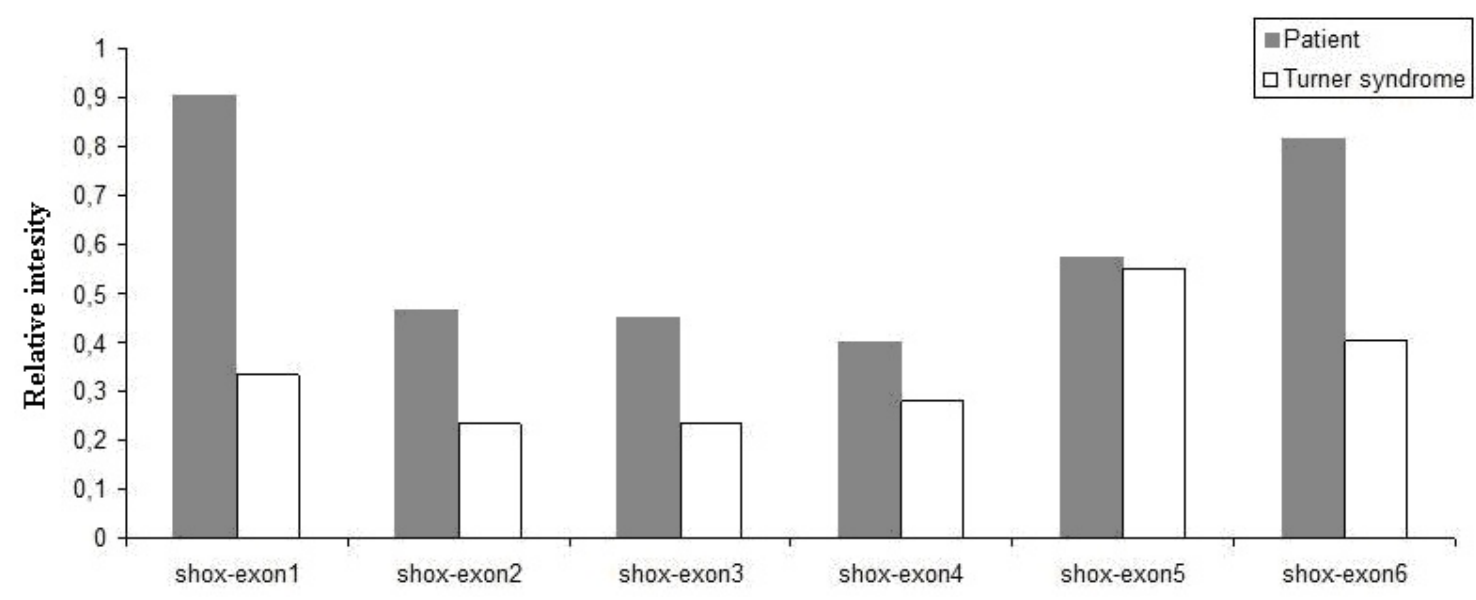

Fig. 2. Multiple ligation dependent probe amplification (MLPA) for detection of SHOX gene deletion. Panel A. Relative expression of exons of SHOX gene in our patient compared to the control (note: the relative expression of exons $2-5$ in our patient was between $45-58 \%$ compared to a healthy female, the cut-off value for diagnosis was 0.6 of the normal value). Panel B: Relative expression of exons of SHOX gene in our patient compared to a patient with cytogenetically confirmed Turner syndrome (expression of exons $4-5$ was similar between these two patients, while the expression of exons 2 - 3 was approximately twice greater in our patient compared to those found in patient with Turner syndrome).

has a particular importance because, the deletion of exons 4-5 of the gene was identified in a patient with ISS, without any radiological signs, highlighting the importance of genetic testing even in patients who present mild clinical symptoms, or suffer from idiopathic short stature.

Based on an accurate genetic diagnosis, the physician can give proper genetic counselling for the patient and his/ her family, informing them about the evolution of the disease and the potential therapeutic plans.

Treatment with GH of children with SHOX deficiency and young females with Turner syndrome was equally efficient in a two-year prospective open-label parallel study [11]. This kind of treatment is effective in ameliorating the growth deficiency and skeletal anomalies found in children with SHOX deficiency [2].

SHOX deficiency disorders are inherited in a pseudoautosomal dominant manner. The offsprings of an individual with SHOX deficiency disorder has a 50\% risk to have a pathogenic SHOX variant. If both parents present SHOX deficiency, the child undergoes a $50 \%$ hazard of developing a SHOX deficiency disorder, $25 \%$ risk of developing Langer mesomelic dysplasia, and $25 \%$ chance of being healthy [13].
In a previous Romanian study Miclea et al. analysed 79 patients presenting short stature with FISH technique using probes for $S H O X$ and centromeric regions. They found one $(2.3 \%)$ case with $S H O X$ deletion in a patient with short stature and normal karyotype [14].

The MLPA is currently the first recommended molecular method for the detection of SHOX gene deletions with a $70-75 \%$ success rate. It is a simple method that permits the concomitant analysis of a wide number of samples and can be applied for the detection of PAR1 deletions and duplications including SHOX and the downstream enhancer region. It also permits the evaluation of the deletion extension. MLPA is less expensive, less time consuming and more sensitive than other techniques (e.g. microsatellite analysis, or FISH technique) [15].

\section{Conclusions}

We are reporting the first case of SHOX haploinsufficiency ISS patient from Romania, specifically a deletion in exons 4-5 of the gene, detected by Multiplex Ligation dependent Probe Amplification (MLPA) technique. This case indicates the necessity of screening for SHOX deletions in patients with idiopathic short stature, especially in chil- 
dren presenting increased sitting height-to-height ratio or decreased extremities-to-trunk ratio.

\section{Conflict of interest}

None to declare.

\section{References}

1. Montalbano A, Juergensen L, Roeth $R$ et al. - Retinoic acid catabolizing enzyme CYP26C1 is a genetic modifier in SHOX deficiency. EMBO Mol Med. 2016;8:1455-1469.

2. Marchini A, Ogata T, Rappold GA - A Track Record on SHOX: From Basic Research to Complex Models and Therapy. Endocr Rev. 2016;37:417-448.

3. Bertalan R, Halász Z - A SHOX gén vizsgálatának klinikai jelentősége alacsonynövésben. Magy Belorv Arch. 2011;64:284-288.

4. Alvarez-Mora MI, Madrigal I, Rodriguez-Revenga L et al. - A 170P mutation in SHOX gene in a patient not presenting with Madelung deformity. J Clin Pathol. 2012;65:844-846.

5. Valetto A, Bertini $\mathrm{V}$, Michelucci A et al. - Short Stature in Isodicentric Y Chromosome and Three Copies of SHOX Gene: Clinical report and Review of Literature. Mol Syndromol. 2016;7:19-25.

6. Choi WB, Seo SH, Yoo WH, Kim SY, Kwak MJ - A Leri-Weill dyschondrosteosis patient confirmed by mutation analysis of $\mathrm{SHOX}$ gene. Ann Pediatr Endocrinol Metab. 2015;20:162-165.

7. Donze SH, Meijer CR, Kant SG et al. - The growth response to GH treatment is greater in patients with SHOX enhancer deletions compared to SHOX defects. Eur J Endocrinol. 2015;173:611-621.

8. Albuisson J, Schmitt S, Baron S, Bezieau S, Benito-Sanz S, Heath KE - Clinical utility gene card for: Leri-Weill dyschondrosteosis (LWD) and Langer mesomelic dysplasia (LMD). Eur J Hum Genet 2012; 20(8). doi:10.1038/ejhg.2012.64

9. Binder G - Short stature due to SHOX deficiency: genotype, phenotype, and therapy. Horm Res Paediatr. 2011;75:81-89.

10. Rappold G, Blum WF, Shavrikova EP et al. - Genotypes and phenotypes in children with short stature: clinical indicators of SHOX haploinsufficiency. J Med Genet. 2007;44:306-313.

11. Blum WF, Crowe BJ, Quigley CA et al. - SHOX Study Group: Growth hormone is effective in treatment of short stature associated with short stature homeobox-containing gene deficiency: Two-year results of a randomized, controlled, multicenter trial. J Clin Endocrinol Metab. 2007;92:219-228.

12. Ross JL, Kowal K, Quigley CA et al.- The phenotype of short stature homeobox gene (SHOX) deficiency in childhood: contrasting children with Leri-Weill dyschondrosteosis and Turner syndrome. J Pediatr. 2005; 147:499-507.

13. Binder G, Rappold GA - SHOX deficiency disorders. In: Pagon RA, Adam MP, Ardinger $\mathrm{HH}$ et al, editors. GeneReviews [Internet]. Seattle, WA: University of Washington 2005. Available at https://www.ncbi.nlm. nih.gov/pubmed/20301394.

14. Miclea DL, Al Khzouz C, Bucerzan S et al. - Assessment of the SHOX gene and chromosomal abnormalities by molecular and classical cytogenetics in patients with short stature. Acta Endo. 2015;11:463469.

15. Funari MF, Jorge AA, Souza SC et al. - Usefulness of MLPA in the detection of SHOX deletions. Eur J Med Genet. 2010;53:234-238. 